\title{
FOETAL DETERIORATION FOLLOWING THIOPENTONE-NITROUS OXIDE ANAESTHESIA IN THE PREGNANT EWE
}

\author{
R.J. Palahniuk and M. Cumming
}

Since Waters introduced the nitrous oxide, oxygen, muscle relaxant technique of anaesthesia in $1944,{ }^{1}$ it has gained wide acceptance among anaesthesiologists for many types of surgery. Because of dissatisfaction with the high incidence of newborn depression seen with cyclopropane anaesthesia, thiopentone induction followed by maintenance with nitrous oxide, oxygen and muscle relaxant has become the popular technique for Caesarean section." Various concentrations of nitrous oxide have been advocated with this technique, but it appeared that less than 60 to 70 per cent was associated with too high an incidence of maternal awareness to be acceptable. ${ }^{3}$ It was felt that sufficient nitrous oxide just to keep the mother asleep should be administered prior to delivery of the baby in order to avoid excessive foetal blood levels of the anaesthetic and the resulting neonatal depression.

Even with this light anaesthetic technique, a large number of babies were born with low Apgar scores, ${ }^{4,5}$ with some studies showing increasing foetal acidosis as the anaesthetic was prolonged. ${ }^{5-7}$ The explanation for this depression was not obvious, but no investigator had undertaken a systematic study of thiopentone induction, endotracheal intubation and nitrous oxide-oxygen maintenance on the mother and foetus. We therefore performed the following study.

\section{Methods and Materials}

Six pregnant ewes carrying a single foetus and within two weeks of term (term $=$ 150 days) were prepared in the following manner. Under halothane-oxygen anaesthesia, catheters were placed in:

1. Maternal femoral artery for monitoring maternal blood pressure, heart rate, blood gases, $\mathrm{pH}$, and base excess.

2. Maternal femoral artery and maternal right atrium (via internal jugular vein) for monitoring maternal cardiac output by the dye-dilution technique.

3. Matemal femoral vein for the administration of drugs.

4. Foetal femoral artery (through a hysterotomy incision) for monitoring foetal blood pressure, heart rate, blood gases, $\mathrm{pH}$, base excess and oxygen saturation.

In addition, a precalibrated Statham electromagnetic flow probe was placed around a main branch of the uterine artery for monitoring uterine blood flow using

R.J. Palahniuk, M.D., and M. Cumming, R.N., B.Sc., Departments of Anaesthesia and Obstetrics and Gynaecology, Health Sciences Centre and University of Manitoba, Winnipeg, Manitoba. Supported by a grant from the Medical Research Council of Canada.

Paper presented at the American Society of Anesthesiologists' meeting, San Francisco, October, 1976.

Address reprint requests to: Dr. R.J. Palahniuk, Department of Anaesthesia, Health Science Centre, Winnipeg, Manitoba R3E OZ3. 
a Statham SP2202 Blood Flowmeter. All incisions were closed and the catheters were brought out to a pocket on the animal's flank.

The animals were allowed to recover from the preparatory surgery for one day before any study was undertaken. Suitability for study was determined by ascertaining that maternal and foetal blood pressure, heart rate and blood gases had returned to the normal range. If the animal was suitable for study, she was placed on her side on the operating table and given oxygen by face mask for a 45 -minute control period when all parameters were measured three times at 15-minute intervals.

Following the control period, the mother was anaesthetized using thiopentone $(4 \mathrm{mg} / \mathrm{kg})$ for induction, and succinylcholine $(60 \mathrm{mg})$ to facilitate tracheal intubation. Following intubation, the ewe was maintained on $\mathrm{N} . \mathrm{O}$ (70 per cent) $-\mathrm{O}_{2}$ ( 30 per cent) with ventilation controlled using an Ohio anaesthesia ventilator and a minute ventilation previously determined to keep maternal $\mathrm{Pa}_{\mathrm{CO}_{2}}$ at approximately control values. Paralysis was maintained using a 0.1 per cent succinylcholine infusion as required to keep the sheep from moving. All variables were then measured at $5,10,15$, and 30 minutes following intubation - the time when the foetus would be most at risk during a Caesarean section anaesthetic.

Maternal and foetal blood pressures and heart rates were measured using Statham strain gauges and a Grass polygraph recorder. All maternal cardiac output measurements were made in duplicate using a Waters XC302 densitometer and Waters DCR-701 cardiac output computer with cardiac green dye as the indicator. Maternal and foetal $\mathrm{Pa}_{2}, \mathrm{~Pa}_{\mathrm{CO}_{2}}$ and $\mathrm{pH}$ were measured at $37^{\circ} \mathrm{C}$ immediately after sampling using a Radiometer $\mathrm{C}_{4} \mathrm{M} 72$ acid-base analyser. All values were corrected to body temperature measured using a Yellow Springs thermometer and rectal probe. Base excess was calculated using the Severinghaus slide rule ${ }^{8}$ and foetal and maternal oxygen saturations were calculated using the appropriate nomogram. ${ }^{\text {? }}$

Changes from control values were compared to control using the Students t-test for paired data. $\mathrm{P}<0.05$ was used as the level of significance.

\section{RESULTS}

Maternal blood pressure and cardiac output did not change significantly from control (Figure 1). Uterine blood flow, however, tended to be reduced about 20 per cent, although only the value at 15 minutes was statistically significant. Uterine vascular conductance, the inverse of resistance, is shown in Figure 2. Again there tended to be a fall of about 20 per cent from control, indicating uterine vasoconstriction during the period of anaesthesia.

Maternal base excess did not change (Figure 3), but maternal $\mathrm{Pa}_{\mathrm{CO}_{2}}$ rose to near 40 torr. Maternal $\mathrm{Pa}_{\mathrm{O}_{2}}$ fell from the control value of 104 torr to 60-80 torr. during the study period. Corresponding maternal oxygen saturations never fell below 90 per cent, however.

Foetal blood pressure did not change significantly from control values (Figure 4), but foetal heart rate tended to be increased.

Foetal acid-base variables (Figure 5) show that the foetus deteriorated after 


\section{MATERNAL CAR DIOVASCULAR VARIABLES}

(土S.E.)

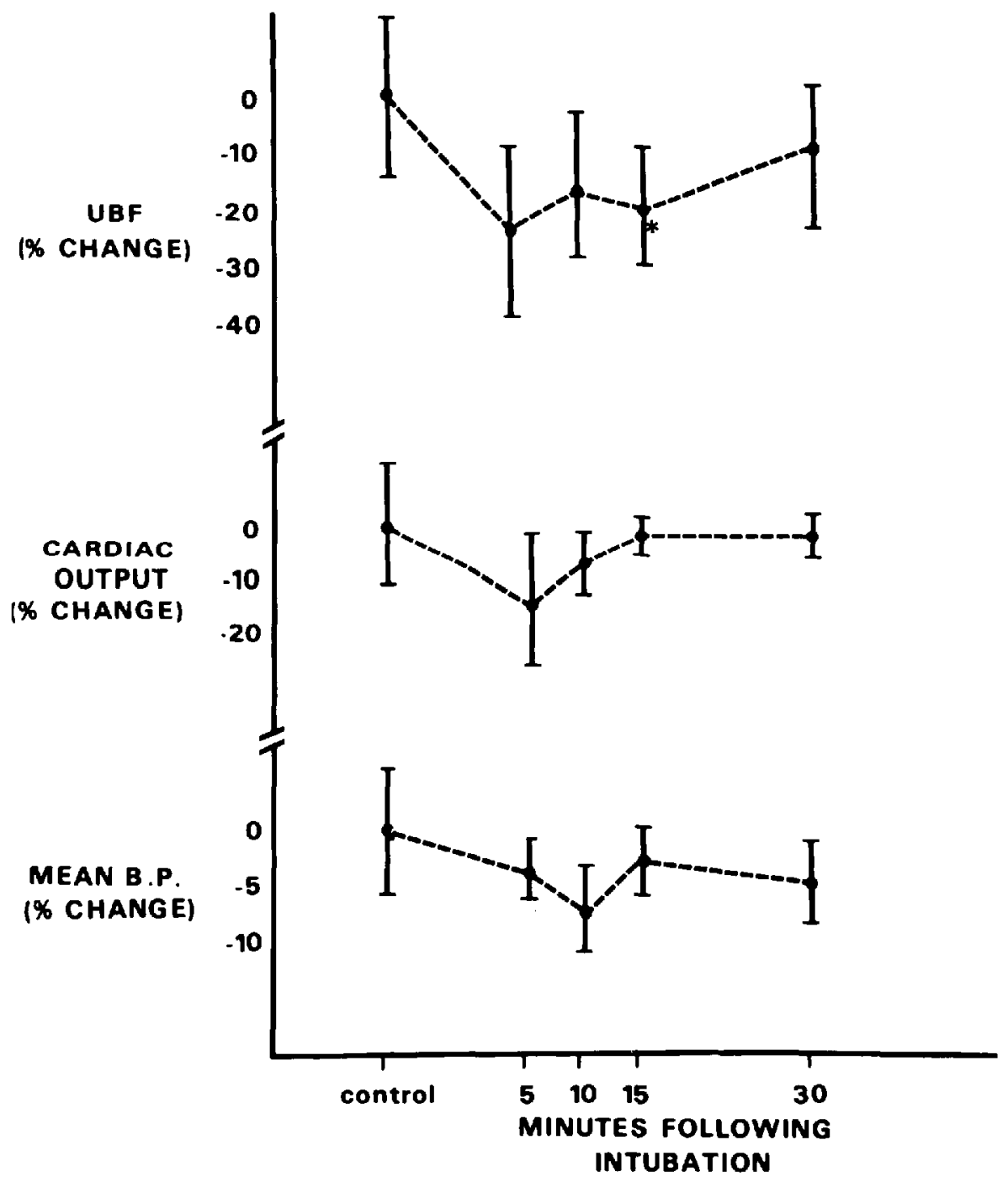

Ficure I, Maternal cardiovascular changes during anaesthesia. Data are plotted as per cent change from control. ${ }^{\circ}=$ significant change from control.

induction of anaesthesia. There was a significant foetal acidosis with a reduction of $\mathrm{pH}$ to 7.01-7.04. This acidosis was mixed metabolic and respiratory in origin as shown by the fall in foetal base excess and the rise in foetal $\mathrm{Pa}_{\mathrm{CO}_{2}}$. Foetal $\mathrm{Pa}_{\mathrm{CO}_{2}}$ rose initially in response to the decreased maternal ventilation, but continued to rise throughout the anaesthetic period despite the stabilization of maternal carbon dioxide levels. 


\section{MATERNAL UTERINE VASCULAR CONDUCTANCE (士 S.E.)}

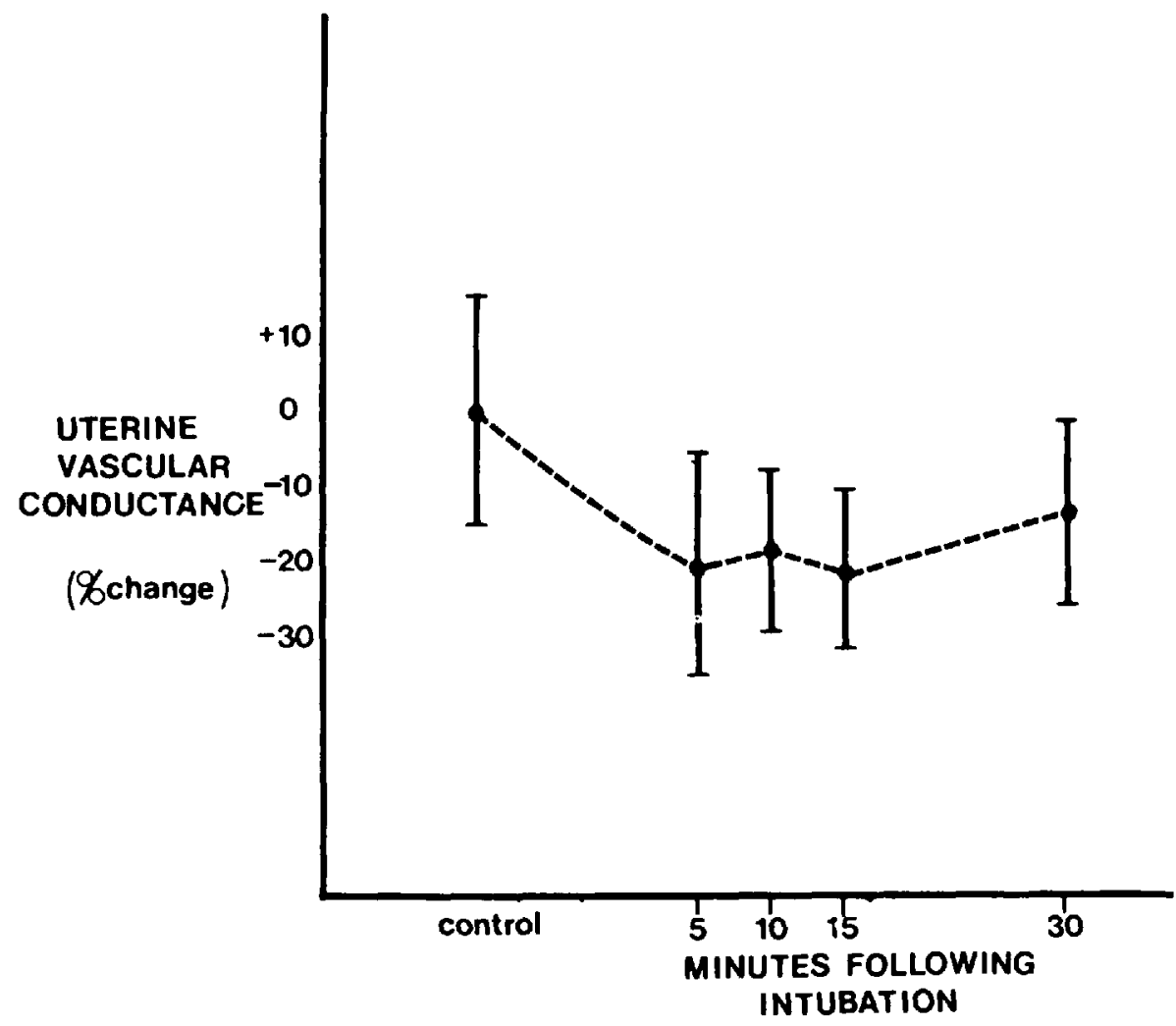

Ficure 2. Uterine vascular conductance during anaesthesia. Uterine vascular conductance = $(1 /$ resistance $)=$ (uterine blood flow/mean arterial blood pressure). Data are plotted as per cent change from control.

Foetal $\mathrm{Pa}_{\mathrm{O}_{2}}$ did not change during the anaesthetic period (Figure 6) but foetal oxygen saturation was reduced significantly as a result of the decrease of foetal $\mathrm{pH}$.

\section{Discussion}

Thiopentone induction, trachael intubation and nitrous oxide-oxygen maintenance was associated with reduced foetal oxygenation and foetal respiratory and metabolic acidosis in the pregnant sheep model. We previously demonstrated that halothane, isoflurane and methoxyflurane anaesthesia in a similar preparation were not associated with any deterioration of the foetus even at moderately deep levels of anaesthesia. ${ }^{10,11}$ In the previous studies, however, induction of anaesthesia 
MATERNAL BLOOD-GAS AND

ACID-BASE VARIABLES ( \pm S.E.)

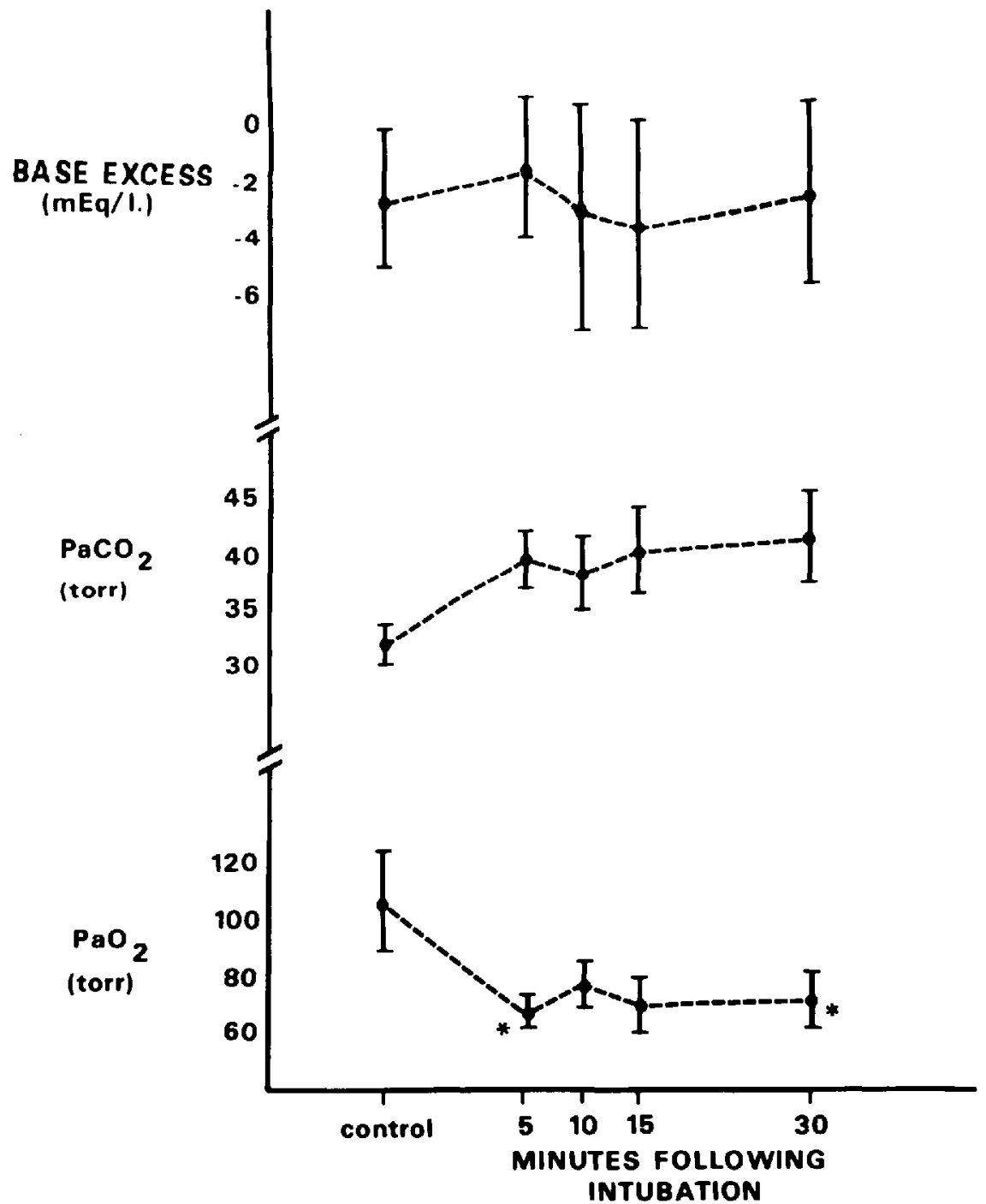

FIGURE 3. Maternal blood gas and acid-base changes during anaesthesia. Data are plotted as absolute values. ${ }^{*}=$ significant change from control.

was performed using the agent being studied with a slow inhalation technique rather than intravenous thiopentone. The present study is more representative of the clinical techniques of general anaesthesia for Caesarean section.

In the present study, maternal $\mathrm{Pa}_{\mathrm{CO}_{2}}$ rose and maternal $\mathrm{Pa}_{\mathrm{O}_{2}}$ fell during the study period as compared to control values. Although the tidal volume and rate of ventilation chosen for these animals after induction of anaesthesia was one which 


\section{FETAL CARDIOVASCULAR VARIABLES (+S.E.)}

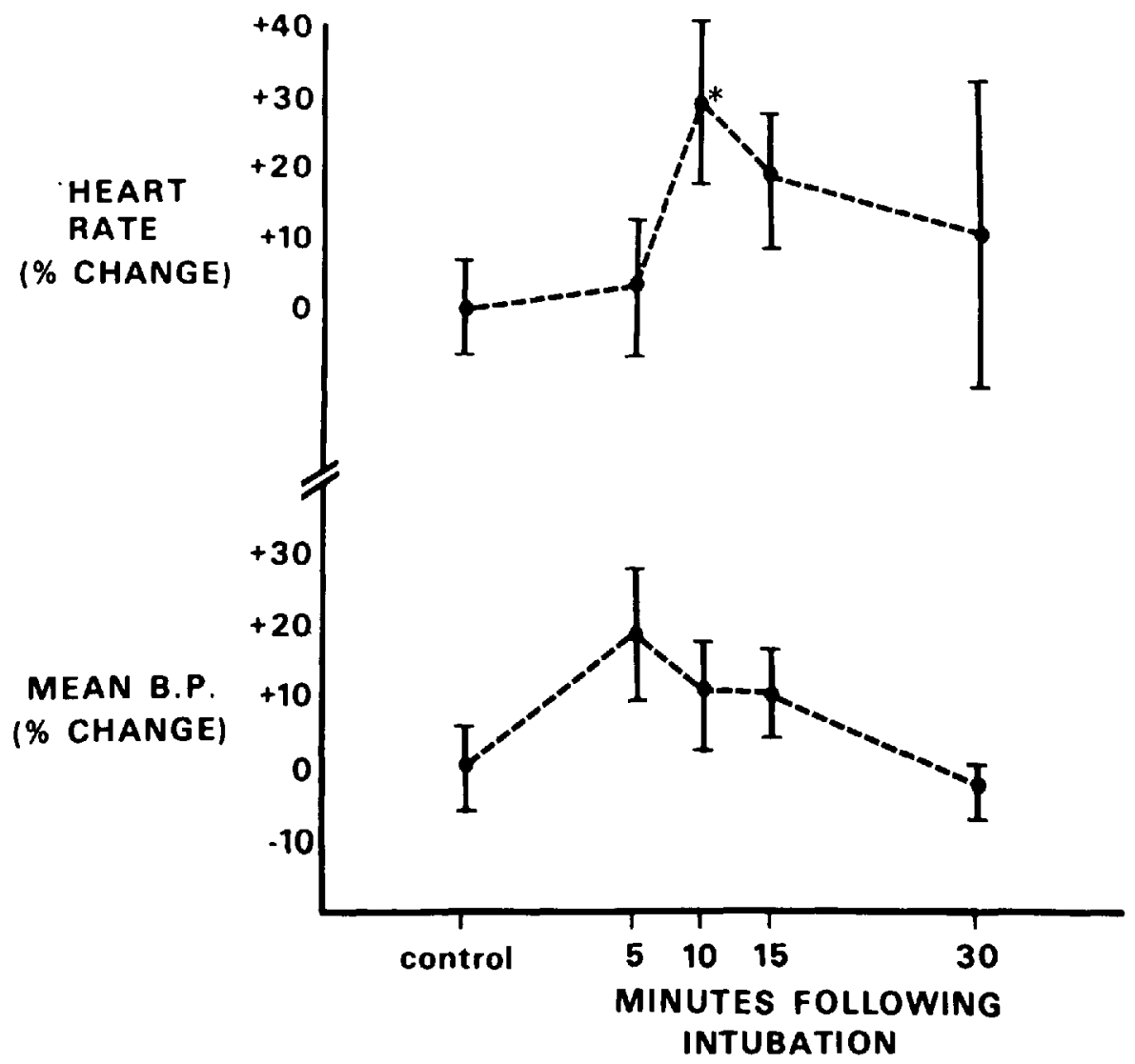

Ficure 4. Foetal cardiovascular changes during anaesthesia. Data are plotted as per cent change from control. ${ }^{\circ}=$ significant change from control.

we previously found to keep maternal $\mathrm{Pa}_{\mathrm{CO}_{2}}$ at about 32 torr, we did find that maternal $\mathrm{Pa}_{\mathrm{CO}_{2}}$ rose in these animals (Figure 3 ). This could not have been responsible for the observed foetal acidosis, however, since foetal $\mathrm{Pa}_{\mathrm{CO}}$ continued to rise (Figure 5) despite stabilization of maternal $\mathrm{Pa}_{\mathrm{CO}_{2}}$, and the foetus also accumulated metabolic acid as shown by the tendency to decreasing foetal base excess (Figure 5). The fall in maternal $\mathrm{Pa}_{0_{2}}$ from control values resulted from a decrease in $\mathrm{FI}_{\mathrm{O}_{2}}$ after induction of anaesthesia, the decrease in alveolar ventilation, and the tendency to increasing ventilation perfusion abnormalities when the animal is laid on her side. Calculated maternal oxygen saturations during the study period remained over 90 per cent, indicating adequate maternal oxygenation. The foetus did not reflect this fall in maternal $\mathrm{Pa}_{2}$ as foetal $\mathrm{Pa}_{\mathrm{O}_{2}}$ stayed constant from control to study periods (Figure 6).

The other important change in the maternal condition was the decrease in uterine blood flow. This was the result of uterine vasoconstriction as shown by the fall in uterine vascular conductance. Throughout the anaesthetic period, the 
FETAL ACID-BASE VARIABLES

(士S.E.)

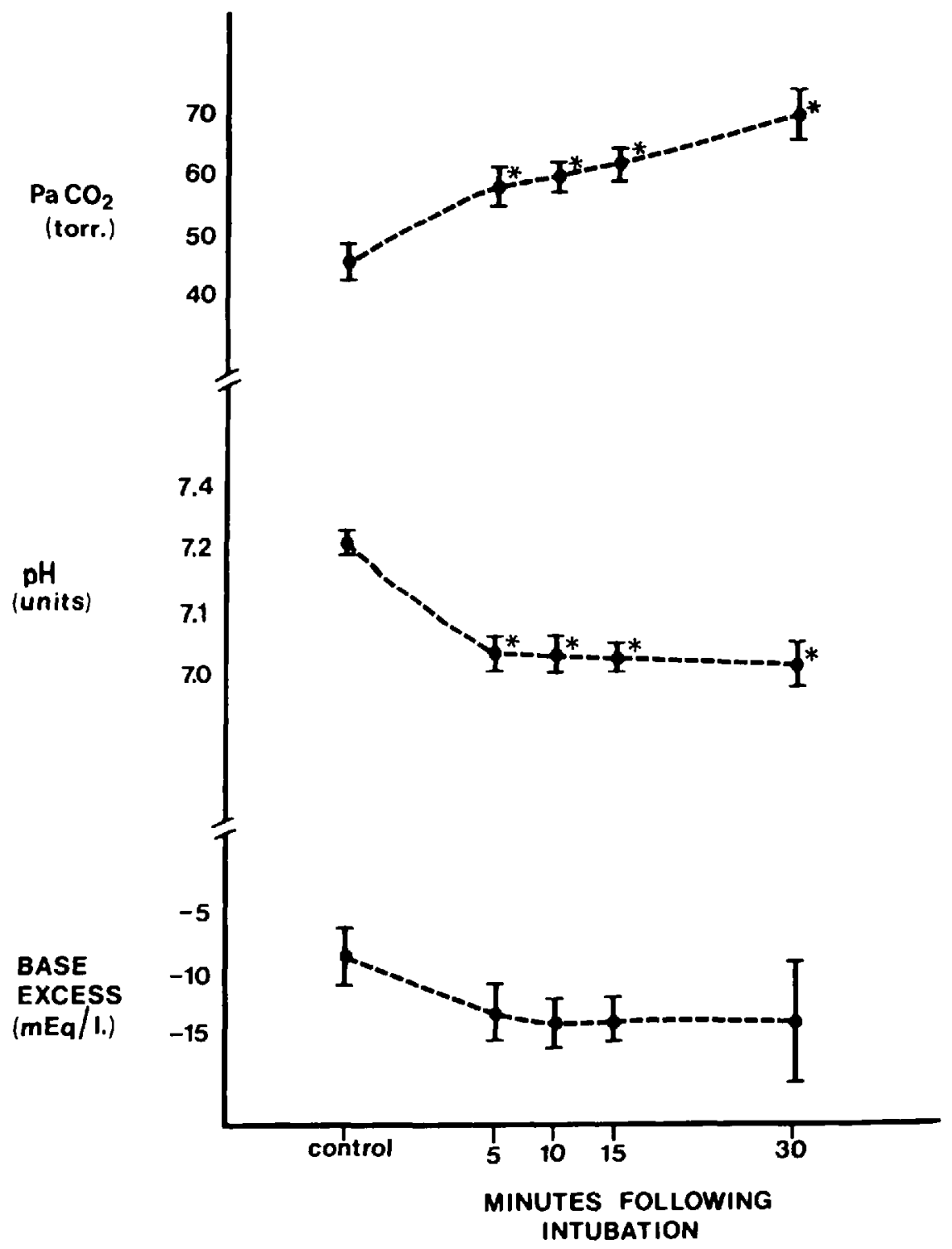

Ficure 5. Foetal acid-base changes during anaesthesia. Data are plotted as absolute values. - = significant change from control.

maternal anaesthesia tended to be rather light and the animal controlled with paralysis - not unlike many Caesarean section anaesthetics. It is attractive to postulate that the stimulus of laryngoscopy, intubation and subsequent light nitrous oxide anaesthesia are associated with catecholamine-induced uterine vasoconstriction and subsequent foetal deterioration. Endogenous and exogenous 
FETAL OXYGENATION ( \pm S.E.)

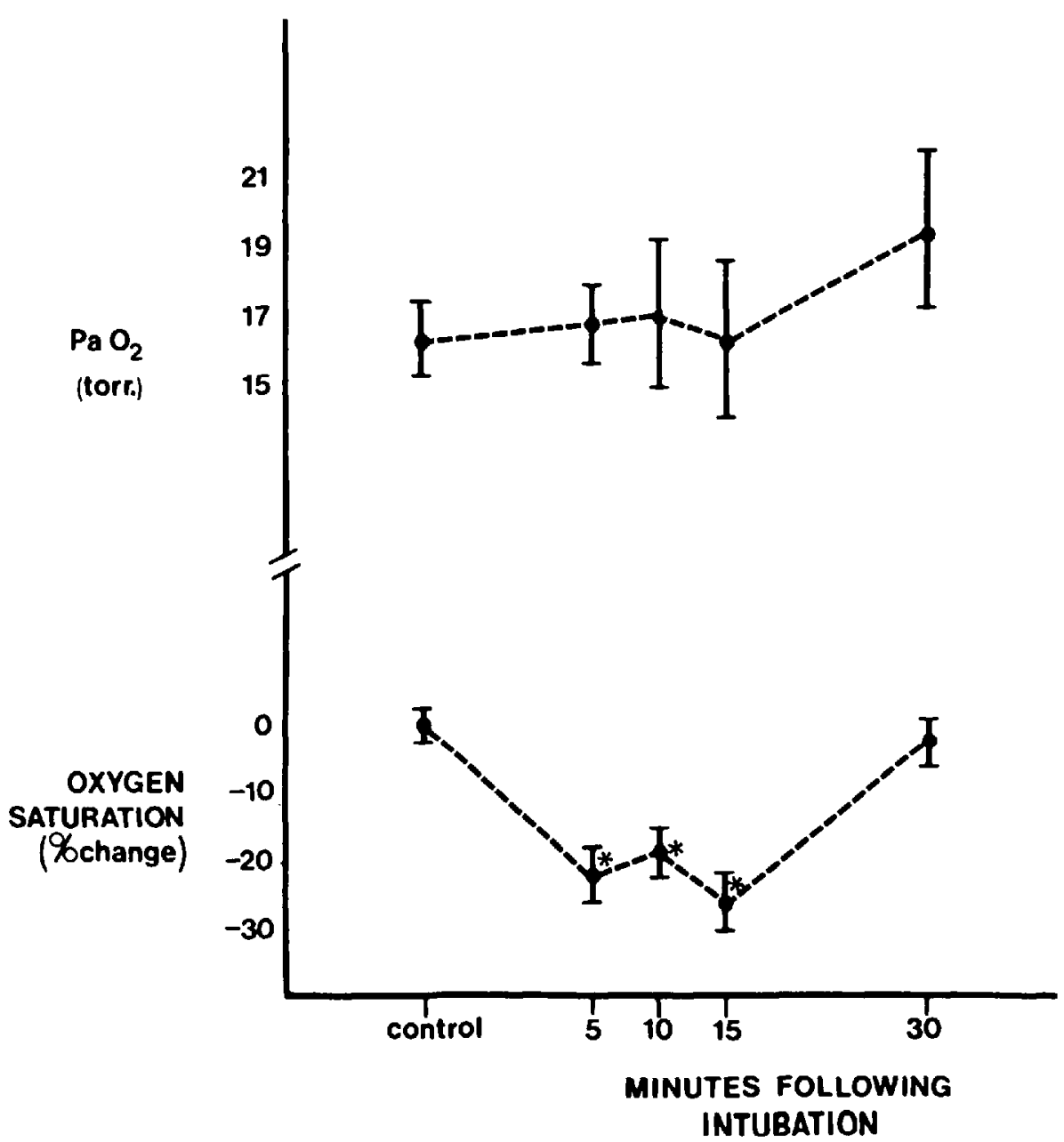

Ficure 6. Foetal oxygenation during anaesthesia. Paoy is plotted as absolute values while oxygen saturation is plotted as per cent change. ${ }^{\circ}=$ significant change from control.

catecholamines have been shown to cause uterine vasoconstriction. ${ }^{12,13}$ This etiology could explain the developing foetal acidosis previously noted in studies of thiopentone nitrous oxide-relaxant anaesthesia for Caesarean section. ${ }^{5-i}$ Nitrous oxide has been shown previously to be associated with sympathetic nervous system stimulation. ${ }^{14}$

Recently, because of the problems with maternal awareness, investigators have been deepening their Caesarean section anaesthetics with volatile agents. ${ }^{15,16}$ They have found that despite the reduction in maternal awareness caused by this deeper anaesthesia, there has been no increase but perhaps even a decrease in 
neonatal depression. This may be further evidence that light maternal anaesthesia may not be optimal for the foetus and neonate, although the major factor responsible for improving the neonatal condition in these studies was thought to be the increased maternal $\mathrm{F}_{\mathrm{O}_{2}}$.

From the results of this study, we conclude that light maternal anaesthesia may result in uterine vasoconstriction, possibly as a result of maternal catecholamine release and subsequent foetal acidosis and hypoxaemia.

\section{SumMary}

Six pregnant sheep were chronically prepared with indwelling catheters in maternal and foetal vessels and a flow probe around a maternal uterine artery. They were anaesthetized the following day with thiopentone and nitrous oxide (70 per cent)-oxygen ( 30 per cent) maintenance with tracheal intubation. Maternal uterine blood flow fell about 20 per cent following induction of anaesthesia. This resulted from uterine vasoconstriction which, in turn, probably resulted from maternal catecholamine release during light anaesthesia. The foetus in utero developed a mixed metabolic and respiratory acidosis and a fall in oxygen saturation. The possibility that light maternal anaesthesia increases rather than decreases neonatal depression is discussed.

\section{RÉSUMÉ}

Dans un premier temps, nous avons placé des cathéters dans les vaisseaux maternels et foetaux de six brebis parturientes, ainsi qu'un débitmètre autour de leur artère utérine. Le lendemain, les mêmes animaux ont été anesthésiés, l'induction se faisant au moyen de thiopental et de succinylcholine et, après intubation, l'anesthésie a été maintenue à l'aide d'un mélange de protoxyde d'azote et d'oxygène ( 70 pour cent $/ 30$ pour cent).

On a observé une dimunition de 20 pour cent du débit sanguin utérin à la suite de l'induction de l'anesthésie. Cette diminution résultait d'une vasoconstriction attribuée à une élévation du taux de catécholamines en anesthésie légère. Chez le fœtus, on a observé une acidose métabolique et une diminution de la saturation d'oxygène.

Les auteurs concluent qu'une anesthésie légère ne diminue pas mais augmente la dépression du foetus.

\section{REFERENCES}

1. Waters, R.M. Nitrous oxide-oxygen and curare. Anesthesiology 5: 618 (1944).

2. Stencer, V.G., Blechner, J.N., Andersen, T.W., Eitzalan, D.V., Cestaric, E., \& Prystowsky, H. Observations on pentothal, nitrous oxide, and succinylcholine anesthesia at Cesarean section. Am. J. Obstet. Gynecol. 99: 690 (1967).

3. Crawford, J.S. Awareness during operative obstetrics under general anaesthesia. Br. J. Anaesth. 43: 179 (1971).

4. Shnider, S.M. Anesthesia for elective Cesarean section, in obstetrical anesthesia. S.M. Shnider Ed. Williams \& Wilkins Co., Baltimore, pp. 94-106 (1970).

5. Fothergill, R.J., Robertson, A., \& Bond, R.A. Neonatal acidaemia related to procrastination at Caesarean section. J. Obstet. Gynaecol. Br. Cwth. 78: 1010 (1971). 
6. Terano, K. Foetal acid-base values during Caesarean section. Lancet 2: 1146 (1968)

7. Fox, G.S. \& Houle, G.L. Acid base studies in elective Caesarean sections during epidural and general anaesthesia. Canad. Anaesth. Soc. J. 18: 60 (1971).

8. Severinghaus, J.W. Blood gas calculator. J. Appl. Physiol. 21: 1108 ( 1966).

9. Hellegens, A.E. \& Schruefer, J.J.A. Nomograms and empirical equations relating oxygen tension, percentage saturation, and $\mathrm{pH}$ in maternal and fetal blood. Am. J. Obstet. Gynecol. 81: 337 (1961).

10. Palahniuk, R.J. \& Shrider, S.M. Maternal and fetal cardiovascular and acid-base changes during halothane and isoflurane anesthesia in the pregnant ewe. Anesthesiology 41: 462 (1974).

11. Smith, J.B., Manninc, F.A., \& Palahniuk, R.J. Maternal and foetal effects of methoxyflurane anaesthesia in the pregnant ewe. Canad. Anaesth. Soc. J. 22: 449 (1975).

12. Rosenfeld, C.R., Barton, M.D., \& Neschea, G. Effects of epinephrine on distribution of blood flow in the pregnant ewe. Am. J. Obstet. Gynecol, 124: 156 (1976).

13. Myers, R.E. Maternal psychological stress and fetal asphyxia: a study in the monkey. Am. J. Obstet. Gynecol. 122:47 (1975).

14. Smith, N.T., Eger, E.I., Stoelting, R.K., Whayne, T.F., Cullen, D., \& Kadis, L.B. The cardiovascular and sympathomimetic responses to the addition of nitrous oxide to halothane in man. Anesthesiology 32: 410 (1970).

15. MoIr, D.D. Anaesthesia for Caesarean section. An evaluation of a method using low concentrations of halothane and 50 per cent oxygen. Br. J. Anaesth. 42: 136 (1970).

16. Latto, I.P. \& Wainwricht, A.C. Anaesthesia for Caesarean section. Analysis of blood concentrations of methoxyflurane using 0.1 per cent methoxyflurane and 40 per cent oxygen. Br. J. Anaesth. 44: 1050 (1972). 